\title{
Residual Stresses Analysis in AISI 316L Processed by Selective Laser Melting (SLM) Treated by Mechanical Post-Processing Treatments
}

\author{
Q. Portella ${ }^{1, a,{ }^{*}}$, M. Chemkhi ${ }^{1,2, b}$, D. Retraint ${ }^{1, c}$, \\ ${ }^{1}$ Charles Delaunay Institute, LASMIS, CNRS, University of Technology of Troyes, 10000 \\ Troyes, France \\ ${ }^{2}$ EPF Graduate School of Engineering, 2 Rue Fernand Sastre, Troyes, France \\ aquentin.portella@utt.fr, 'bmahdi.chemkhi@epf.fr, 'cdelphine.retraint@utt.fr
}

Keywords: Residual Stresses, 316L, Selective Laser Melting, SMAT, Roughness, Micro-Hardness

\begin{abstract}
Selective Laser Melting (SLM) is a metal additive manufacturing process widely used in industry for its extraordinary versatility and minimal waste of material. Mechanical properties of SLM parts strongly depend on the process parameters such as power, scanning speed, hatch space and scanning strategy. Depending on these latter parameters, the SLM parts can be porous or fully dense. However, the high thermal gradients which are characteristic of this process induce complex distributions of residual stresses and defects such as micro-cracks. In the case where these internal stresses have a negative effect on the physical and mechanical integrity of SLM parts, the well-known solution proposed to reduce them is a post-heat treatment. Incidentally, superficial compressive residual stresses can also be generated by mechanical treatments and can improve the fatigue performance of the treated parts. The aim of this work is to examine the effect of Surface Mechanical Attrition Treatment (SMAT) on the residual stresses present in AISI 316L parts processed by SLM. The X-ray diffraction (XRD) results show that this mechanical treatment is a promising method to avoid the negative effect of tensile residual stresses resulting from the SLM process and can introduce a beneficial superficial compressive residual stress state. Moreover, work hardening and surface roughness were evaluated in all the untreated and SMATed samples.
\end{abstract}

\section{Introduction}

Residual stresses are associated to any fabrication process and can actually be harmful for the samples, leading to lower mechanical properties or even plastic deformation [1]. Manufacturers usually prevent the negative effect of these stresses by using post-heat treatments that fix the desired microstructure and mechanical properties depending on the thermal stability of parts. Another way to reduce these residual stresses is the use of a post-mechanical treatment, such as SMAT (Surface Mechanical Attrition Treatment) [2]. During this treatment, the sample is impacted by a multitude of balls which moves in multiple directions contrary to shot peening where the shot direction is generally normal to the surface sample or presents a specific angle [3]. Consequences of this mechanical post-treatment are multiple, depending on the intensity of the treatment. It can deeply affect the microstructure of the treated part, generate a superficial nanocrystalline layer [4], increase the micro-hardness [5], reduce the roughness [6], or even enhance the nitrogen diffusion [7].

In this paper, the studied material is a 316L austenitic stainless steel (SS) which was produced by a metallic additive manufacturing process, Selective Laser Melting (SLM). These new methods of manufacturing pave the way to new structures, such as porous ones [8], with many advantages, like less waste of matter or faster manufacturing but can also introduce defects like 
cracks, internal porosity, poor surface state and residual stresses [1]. Parts made by SLM usually exhibit tensile residual stresses [8]. Several authors who have studied the effect of SMAT on conventional (cast, wrought) 316L SS showed that SMAT can introduce superficial compressive residual stresses [10]. To the best of the authors' knowledge, there is no previous study investigating the effect of SMAT on the mechanical properties and thermal residual stresses of additive manufactured parts. In this work, the SMAT effect on SLM 316L SS is studied in terms of residual stresses, roughness, micro-hardness, phase analysis and tensile behaviour.

\section{Materials and methods}

The 316L powder used to produce the SLM samples was obtained by nitrogen atomisation process. The particles are spherical with a size ranging between 10 and $45 \mu \mathrm{m}$. The chemical analysis of the 316L powder is presented in Table 1.

Table 1 : Chemical analysis of the 316L powder

\begin{tabular}{|c|c|c|c|c|c|c|c|c|c|c|}
\hline Element & Fe & $\mathrm{C}$ & $\mathrm{Si}$ & $\mathrm{Mn}$ & $\mathrm{P}$ & $\mathrm{S}$ & $\mathrm{Cr}$ & $\mathrm{Ni}$ & $\mathrm{Mo}$ & $\mathrm{N}$ \\
wt\% & Balance & 0.01 & 0.53 & 1.12 & 0.03 & 0.013 & 16.61 & 10.18 & 2.15 & 0.08 \\
\hline
\end{tabular}

The 316L samples were produced by the Platinium 3D Technology Platform. The geometry and dimensions of the samples are described in Figure 1.
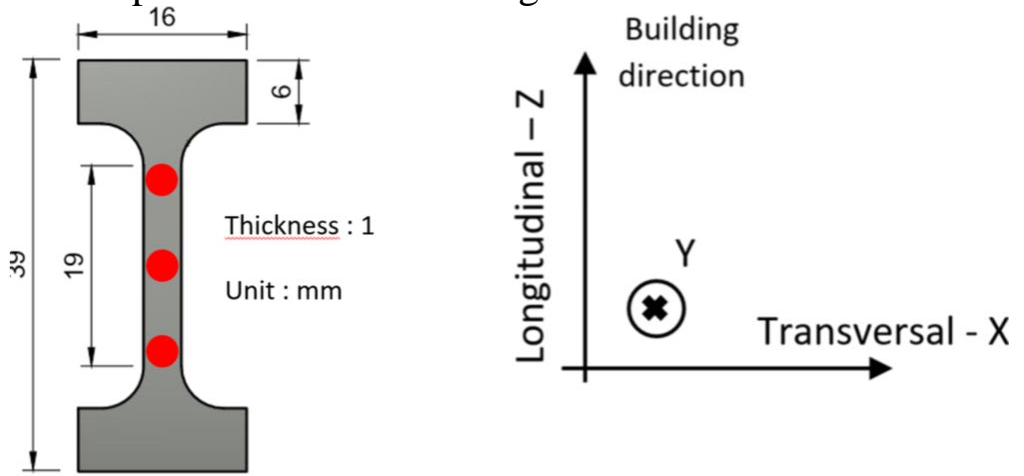

Fig. 1 : Sample geometry according to ISO 6892-1 [11]

Samples were made under Ar atmosphere with a residual oxygen fraction inside the chamber equal to $0.02 \%$. The building platform was heated at $150^{\circ} \mathrm{C}$ during the entire process. The samples were built vertically, according to Fig. 1., The vertical position of the samples was chosen to ensure the same surface state between the two sides of each sample. The layer thickness was set to $50 \mu \mathrm{m}$ and the hatch space to $80 \mu \mathrm{m}$.

The Vickers micro-hardness measurements were performed using a FM300e equipment from the Future-Tech Company, with a load of 25g during 10s. The measurements were performed in the cross-section perpendicular to the bilding direction. Each hardness experimental value is an average of 7 indentations along the transversal axis performed at the same distance from the surface.

Roughness measurements were performed using a Surtronic 3+ equipment from the TaylorHobson company. The evaluation length for Ra parameter was performed in accordance with the standard NF EN ISO 4287 [12]. Before performing the measurements, two tests were carried out on a reference specimen. After these validation tests, the obtained results are an average of 8 measurements. Residual stresses were measured at the surface of each sample, at three different points in the longitudinal and transverse directions (see Fig.1) in order to check the homogeneity of the superficial residual stress state. The X-ray diffraction $\sin ^{2} \psi$ method was used with $\mathrm{Cr} \mathrm{K} \alpha$ wavelength.Tensile tests were performed at room temperature using a 5KN Microtest Extended Tensile tester equipment from Deben UK Ltd. with a motor speed of $1.25 \mathrm{~mm} / \mathrm{min}$. The SMAT parameters that were used are summarised in Table 2. 
Table 2 : SMAT treatment

\begin{tabular}{|c|c|}
\hline Configuration of treatment & SMAT Very High (SVH) \\
\hline Duration of treatment & $20 \mathrm{~min}$ \\
\hline Nature/diameter of shot & $100 \mathrm{Cr} 6 / 3 \mathrm{~mm}$ \\
\hline Amplitude & $27 \mu \mathrm{m}$ \\
\hline
\end{tabular}

\section{Results and Discussion}

Surface roughness: To evaluate the surface roughness, the most universally used roughness parameter for general quality control is the arithmetic average height $\mathrm{Ra}$ [13]. As-fabricated parts have a roughness average of $11 \pm 1 \mu \mathrm{m}$ on each side of the samples. This value of roughness is similar to what was found by other authors who worked on 316L SLM, like [14], [15] with a measured Ra of $\sim 12 \mu \mathrm{m}$. This similarity in roughness measurement is due to the nominal size of powder initially used. The general parameters for fabrication (power, scan speed, thickness, hatch space) are indeed different but the size of the used powder is the same $(10-45 \mu \mathrm{m})$. The surface of the as-fabricated samples is a compound of partially melted powder, which is at the origin of this roughness value.

As shown in Figure 2, the SMAT drastically decreases the surface roughness up to 95\% so that the surface roughness reaches a value of $1.2 \mu \mathrm{m}$.

SMAT exists among other methods designed to reduce surface roughness. Yasa and Kruth used laser re-melting to lower the surface roughness from $12 \mu \mathrm{m}$ to $1.5 \mu \mathrm{m}$ [15].

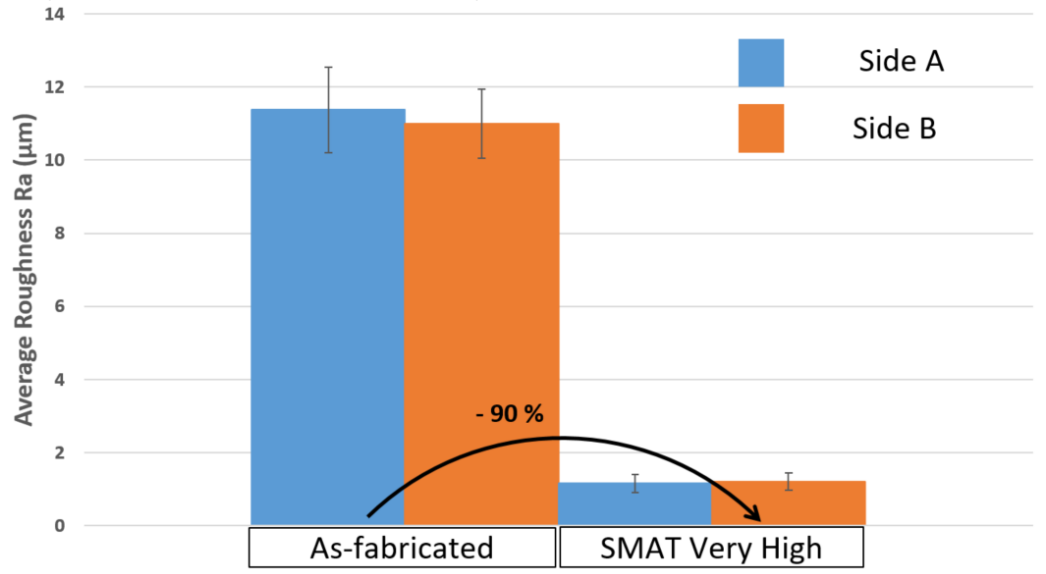

Fig. 2 : Evolution of the surface roughness $R a$

Micro-hardness: In order to have some indication on the micro-hardness of parts produced by additive manufacturing, previous studies reveal a value of micro-hardness of 316L SS SLM between $210 \mathrm{HV}_{1000}$ and $240 \mathrm{HV}_{1000}$ : [16] speaks about $235 \mathrm{HV}$, [17] reports values between 210 and $240 \mathrm{HV}_{1000}$, [18] $216 \mathrm{HV}_{1000}$, [19] $228 \mathrm{HV}$, [11] $225 \mathrm{HV}_{1000}$. In our case, the as-fabricated sample shows a micro-hardness around $240 \mathrm{HV}_{0.025}$ near the surface and $205 \mathrm{HV}_{0.025}$ in the bulk which is in accordance with literature. As shown in Fig. 3, SMAT has increased the microhardness by more than $50 \%$ in the bulk of the sample. The strain hardening effect has affected the entire width of the sample. For the as-fabricated one, the evolution of the micro-hardness shows an increase from the centre to the surface, a trend which is much less present after the SVH treatment.

Residual stresses: The as-fabricated sample shows tensile residual stresses up to 30-40 MPa in the transversal direction and $100 \mathrm{MPa}$ in the longitudinal direction (see Fig. 1). In the work of [9] the evaluated residual stresses are approximatively equal to $200 \mathrm{MPa}$ with an evolution from 100 to $150 \mathrm{MPa}$ in the sample's thickness. Fig. 4 shows that SMAT generates superficial compressive residual stresses ranging from -170 MPa to -280 MPa. The differences recorded between the three different points of measurement is rather small. Moreover, it has to be 
underlined that, these measurements do not give any information on the maximum compressive residual stress which is reached after SMAT; on the one hand, Roland et al. [10] indicate that the highest compressive residual stress value after SMAT is reached at the surface of a 316L steel sample, but on the other hand, Gallitelli et al. [20] show that the maximum compressive residual stresses is reached below the surface for a titanium sample subjected to SMAT. Residual stress profile measurements are thus under progress using X-ray diffraction coupled with electropolishing steps.

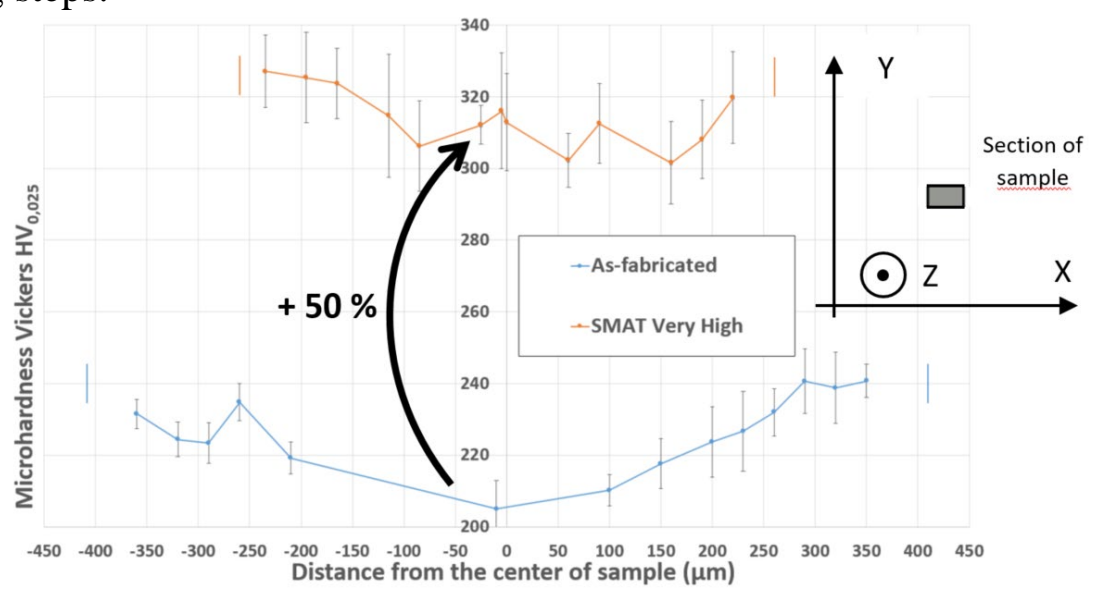

Fig. 3 : Evolution of micro-hardness profiles according to the transversal direction for different sample conditions
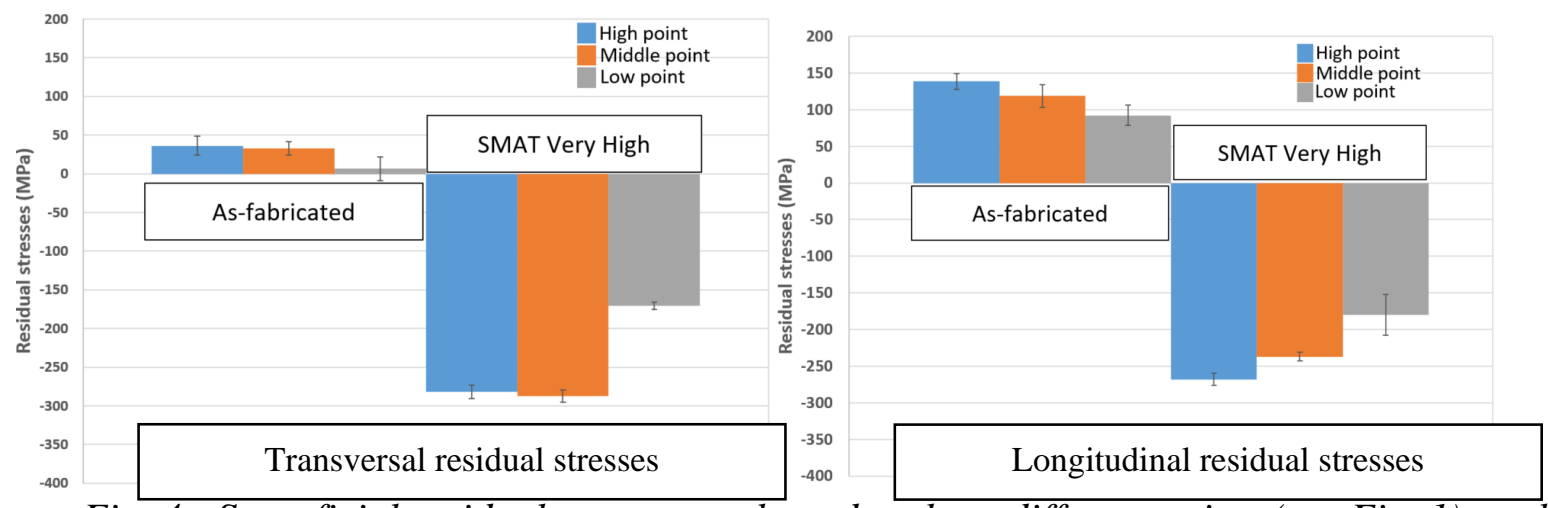

Fig. 4 : Superficial residual stresses evaluated at three different points (see Fig. 1) on the untreated and SMATed surface samples

Tensile tests: Fig. 5 represents the tensile curves obtained for the untreated and SMATed samples. It shows that SMAT modifies the mechanical behaviour drastically, with a high reduction of elongation and an increase in yield strength and tensile strength. Indeed, asfabricated samples exhibit a uniform elongation of $31.19 \pm 2.33 \%$ with mechanical properties of $557 \pm 15$ MPa for Yield Strength (YS) and $859 \pm 11$ MPa for Ultimate Tensile Test (UTS). SVH treatment increases YS by $53 \%$ reaching a value of $852 \pm 38 \mathrm{MPa}$ and $7 \%$ for UTS setting the value at $918 \pm 6 \mathrm{MPa}$. The biggest modification is for the Uniform Elongation (UE) which decreases by $71.7 \%$, with a final value of $7.78 \pm 0.6 \%$. These modifications induced by SMAT on the YS, UTS and UE strongly depend on the treatment intensity: Roland et al. [5] showed the same tendency for conventional 316 L SS before and after SMAT; the more intense the treatment is, the more affected the mechanical properties are [21].

\section{Conclusion}

This study shows that 316L SS SLM subjected to SMAT can have its properties strongly modified (micro-hardness, surface roughness, residual stresses) in order to improve its mechanical behaviour. Other SMAT treatments with different configurations (lower intensity) 
are currently under way in order to evaluate their effects on this stainless steel properties. Residual stresses should be examined at different depths below the untreated and SMATed surfaces to identify their evolution. SMAT proved to be especially promising to enhance several mechanical properties such as yield and ultimate strengths, nevertheless, it also decreases the ductility (elongation). Besides, additional experiments are under progress in order to understand the effect of SMAT on the strengthening of SLM parts.

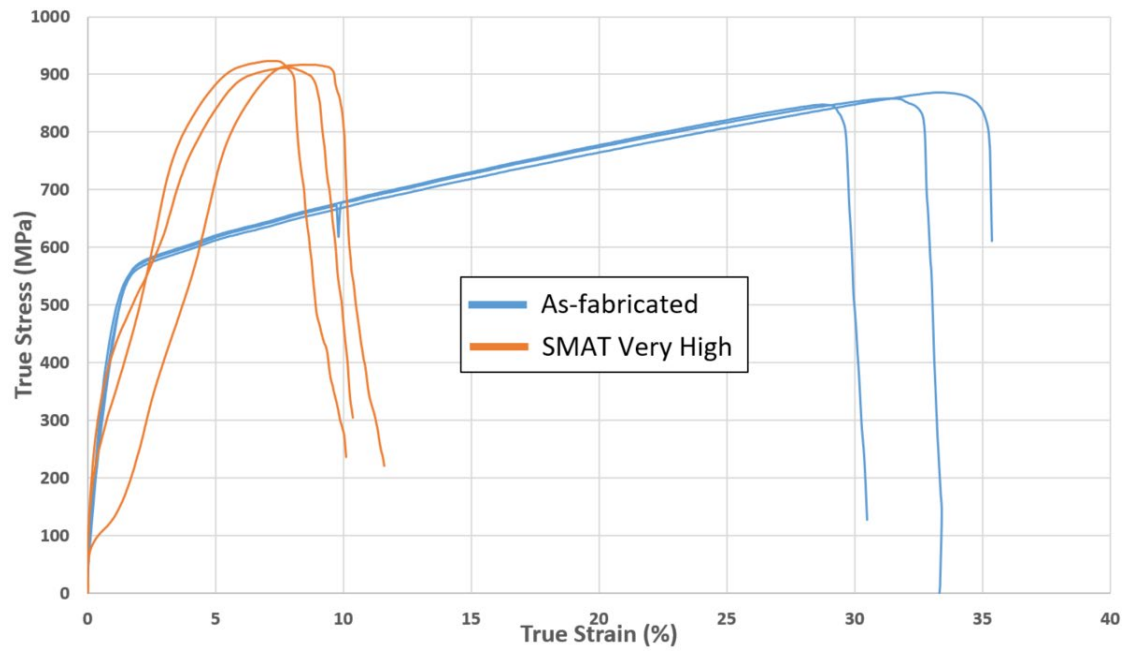

Fig. 5 : Tensile tests

\section{Acknowledgements}

The authors wish to thank the Aube Department Council (France) and Europe (FEDER) for financial support. The PLATINIUM3D Technology Platform is also acknowledged for providing the samples.

\section{References}

[1] W. J. Sames, F. A. List, S. Pannala, R. R. Dehoff, and S. S. Babu, “The metallurgy and processing science of metal additive manufacturing,” Int. Mater. Rev., vol. 61, no. 5, pp. 315360, Jul. 2016. https://doi.org/10.1080/09506608.2015.1116649

[2] K. Lu and J. Lu, "Nanostructured surface layer on metallic materials induced by surface mechanical attrition treatment,” Mater. Sci. Eng. A, vol. 375-377, pp. 38-45, Jul. 2004. https://doi.org/10.1016/j.msea.2003.10.261

[3] B. Arifvianto, Suyitno, M. Mahardika, P. Dewo, P. T. Iswanto, and U. A. Salim, "Effect of surface mechanical attrition treatment (SMAT) on microhardness, surface roughness and wettability of AISI 316L,” Mater. Chem. Phys., vol. 125, no. 3, pp. 418-426, Feb. 2011. https://doi.org/10.1016/j.matchemphys.2010.10.038

[4] Y. Samih, B. Beausir, B. Bolle, and T. Grosdidier, "In-depth quantitative analysis of the microstructures produced by Surface Mechanical Attrition Treatment (SMAT),” Mater. Charact., vol. 83, pp. 129-138, Sep. 2013. https://doi.org/10.1016/j.matchar.2013.06.006 [5] T. Roland, D. Retraint, K. Lu, and J. Lu, "Enhanced mechanical behavior of a nanocrystallised stainless steel and its thermal stability,” Mater. Sci. Eng. A, vol. 445-446, pp. 281-288, Feb. 2007. https://doi.org/10.1016/j.msea.2006.09.041

[6] B. Arifvianto, Suyitno, and M. Mahardika, "Effects of surface mechanical attrition treatment (SMAT) on a rough surface of AISI 316L stainless steel,” Appl. Surf. Sci., vol. 258, no. 10, pp. 4538-4543, Mar. 2012. https://doi.org/10.1016/j.apsusc.2012.01.021

[7] M. Chemkhi, D. Retraint, A. Roos, and C. Demangel, "Role and effect of mechanical polishing on the enhancement of the duplex mechanical attrition/plasma nitriding treatment of AISI 316L steel,” Surf. Coat. Technol., vol. 325, pp. 454-461, Sep. 2017. https://doi.org/10.1016/j.surfcoat.2017.06.052 
[8] J. Čapek et al., "Highly porous, low elastic modulus 316L stainless steel scaffold prepared by selective laser melting,” Mater. Sci. Eng. C, vol. 69, pp. 631-639, Dec. 2016. https://doi.org/10.1016/j.msec.2016.07.027

[9] T. Simson, A. Emmel, A. Dwars, and J. Böhm, "Residual stress measurements on AISI 316L samples manufactured by selective laser melting,” Addit. Manuf., vol. 17, pp. 183-189, Oct. 2017. https://doi.org/10.1016/j.addma.2017.07.007

[10]T. Roland, D. Retraint, K. Lu, and J. Lu, "Fatigue life improvement through surface nanostructuring of stainless steel by means of surface mechanical attrition treatment," Scr. Mater., vol. 54, no. 11, pp. 1949-1954, Jun. 2006.

https://doi.org/10.1016/j.scriptamat.2006.01.049

[11] “ISO 6892-1:2009(en), Metallic materials — Tensile testing — Part 1: Method of test at room temperature.”

[12] “ISO 4287:1997 - Geometrical Product Specifications (GPS) -- Surface texture: Profile method -- Terms, definitions and surface texture parameters.”

[13]E. S. Gadelmawla, M. M. Koura, T. M. A. Maksoud, I. M. Elewa, and H. H. Soliman, “Roughness parameters,” J. Mater. Process. Technol., vol. 123, no. 1, pp. 133-145, Apr. 2002. https://doi.org/10.1016/S0924-0136(02)00060-2

[14]J. A. Cherry, H. M. Davies, S. Mehmood, N. P. Lavery, S. G. R. Brown, and J. Sienz, "Investigation into the effect of process parameters on microstructural and physical properties of 316L stainless steel parts by selective laser melting,” Int. J. Adv. Manuf. Technol., vol. 76, no. 58, pp. 869-879, Feb. 2015. https://doi.org/10.1007/s00170-014-6297-2

[15]E. Yasa and J.-P. Kruth, "Microstructural investigation of Selective Laser Melting 316L stainless steel parts exposed to laser re-melting,” Procedia Eng., vol. 19, pp. 389-395, Jan. 2011. https://doi.org/10.1016/j.proeng.2011.11.130

[16]I. Tolosa, F. Garciandía, F. Zubiri, F. Zapirain, and A. Esnaola, "Study of mechanical properties of AISI 316 stainless steel processed by 'selective laser melting', following different manufacturing strategies,” Int. J. Adv. Manuf. Technol., vol. 51, no. 5-8, pp. 639-647, Nov. 2010. https://doi.org/10.1007/s00170-010-2631-5

[17] E. Liverani, S. Toschi, L. Ceschini, and A. Fortunato, "Effect of selective laser melting (SLM) process parameters on microstructure and mechanical properties of 316L austenitic stainless steel,” J. Mater. Process. Technol., vol. 249, pp. 255-263, Nov. 2017.

https://doi.org/10.1016/j.jmatprotec.2017.05.042

[18]Z. Sun, X. Tan, S. B. Tor, and W. Y. Yeong, "Selective laser melting of stainless steel 316L with low porosity and high build rates,” Mater. Des., vol. 104, pp. 197-204, Aug. 2016.

https://doi.org/10.1016/j.matdes.2016.05.035

[19]A. A. Deev, P. A. Kuznetcov, and S. N. Petrov, “Anisotropy of Mechanical Properties and its Correlation with the Structure of the Stainless Steel 316L Produced by the SLM Method," Phys. Procedia, vol. 83, pp. 789-796, Jan. 2016. https://doi.org/10.1016/j.phpro.2016.08.081 [20]D. Gallitelli, D. Retraint, and E. Rouhaud, "Comparison between Conventional Shot Peening (SP) and Surface Mechanical Attrition Treatment (SMAT) on a Titanium Alloy,” Adv. Mater. Res., vol. 996, pp. 964-968, Aug. 2014.

https://doi.org/10.4028/www.scientific.net/AMR.996.964 [21] T. Roland, D. Retraint, K. Lu, and J. Lu, "Generation of Nanostructures on 316L Stainless Steel and Its Effect on Mechanical Behavior,” Materials Science Forum, 2005.

https://doi.org/10.4028/0-87849-969-5.625 